\title{
85646 - EFEITOS DO MÉTODO ISOSTRETCHING NA POSTURA E FLEXIBILIDADE DE IDOSAS
}

\author{
Pôster - Gerontologia
}

\author{
Gisele Oltramari Meneghini / Meneghini, GO / FSG Centro Universitário da Serra Gaúcha; \\ Jaqueline Marostica Schu / Schu, JM / FSG Centro Universitário da Serra Gaúcha; \\ José Davi Oltramari / Oltramari, JD / FSG Centro Universitário da Serra Gaúcha; \\ Daiane Giacomet / Giacomet, D / FSG Centro Universitário da Serra Gaúcha; \\ Alexandra Renosto / Renosto, A / FSG Centro Universitário da Serra Gaúcha; \\ Alenia Varela Finger Minuscoli / Minuscoli, AVF / FSG Centro Universitário da Serra Gaúcha
}

Introdução: O termo "idoso" refere-se à indivíduos maiores de 60 anos, sendo que com o processo fisiológico de envelhecimento sofrem importantes alterações posturais, gerando encurtamentos musculares, tendinosos e do tecido conjuntivo. O método Isostretching aborda a reeducação da postura, acarretando em um aumento da flexibilidade e correções de curvas fisiológicas. Desta forma, objetivou-se com este estudo, verificar os efeitos do Método Isostretching na postura e flexibilidade de idosas. Materiais e métodos: $\mathrm{O}$ estudo caracterizou-se por um ensaio quase experimental, onde as participantes foram avaliadas e reavaliadas pelos seguintes instrumentos: uma ficha de avaliação fisioterapêutica (anamnese), avaliação postural (baseada na avaliação Ângela Santos), fotogrametria computadorizada (avaliação postural), Teste do terceiro dedo ao chão (flexibilidade) e escala visual analógica (dor). Resultados: Obteve-se significativos ganhos com relação ao alívio da dor e ganho de flexibilidade após a intervenção com o Método Isostretching. Comparando os momentos pré e pós intervenção, observou-se diferença estatisticamente significativa na redução da dor, ganho de flexibilidade que resultou em redução dos ângulos coxofemoral e tibiotarsico, melhora postural em relação a protusão cervical e a flexão de joelhos. Durante o teste do terceiro dedo ao chão verificou-se os ângulos da cadeia posterior, onde pré intervenção 16 participantes possuíam encurtamento muscular e alteração nos ângulos coxofemoral e tibiotarsico, após a intervenção apenas 1 participante permaneceu com encurtamento muscular. Em relação a escala visual analógica inicialmente 5,9\% das participantes apresentavam quadro álgico, após 2,23\% ainda apresentavam sintomas. Consideração final: $\mathrm{O}$ método Isostretching proporcionou aumento da flexibilidade de cadeia posterior, alivio do quadro álgico e promoveu melhora postural. 